\title{
Acquired homotypic and heterotypic immunity against oculogenital Chlamydia trachomatis serovars following female genital tract infection in mice
}

\author{
Joseph M Lyons*1, Servaas A Morré2 ${ }^{2}$ Lucy P Airo-Brown³ ${ }^{3}$ A Salvador Peña ${ }^{2}$ \\ and James I Ito ${ }^{1}$
}

\begin{abstract}
Address: ${ }^{1}$ Department of Infectious Diseases, City of Hope National Medical Center and Beckman Research Institute, Duarte, California 91010, USA, ${ }^{2}$ Laboratory of Immunogenetics, Section Immunogenetics of Infectious Diseases, VU University Medical Center, Amsterdam, The Netherlands and ${ }^{3}$ Analytical Cytometry Laboratory, City of Hope National Medical Center and Beckman Research Institute, Duarte, California 91010, USA

Email: Joseph M Lyons* - jlyons@coh.org; Servaas A Morré - samorretravel@yahoo.co.uk; Lucy P Airo-Brown - lbrown@coh.org; A Salvador Peña - as.pena@vumc.nl; James I Ito - jito@coh.org

* Corresponding author
\end{abstract}

Published: 17 November 2005

BMC Infectious Diseases 2005, 5:105 doi:10.1186/147/-2334-5-105

This article is available from: http://www.biomedcentral.com/I47/-2334/5//05

(C) 2005 Lyons et al; licensee BioMed Central Ltd.

This is an Open Access article distributed under the terms of the Creative Commons Attribution License (http://creativecommons.org/licenses/by/2.0), which permits unrestricted use, distribution, and reproduction in any medium, provided the original work is properly cited.

\begin{abstract}
Background: Chlamydia trachomatis is the most common sexually transmitted bacterial pathogen causing female genital tract infection throughout the world. Reinfection with the same serovar, as well as multiple infections with different serovars, occurs in humans. Using a murine model of female $C$. trachomatis genital tract infection, we determined if homotypic and/or heterotypic protection against reinfection was induced following infection with human oculogenital strains of $C$. trachomatis belonging to two serovars ( $D$ and $H)$ that have been shown to vary significantly in the course of infection in the murine model.
\end{abstract}

Methods: Groups of outbred CF-I mice were reinfected intravaginally with a strain of either serovar D or $\mathrm{H}$, two months after initial infection with these strains. Cellular immune and serologic status, both quantitative and qualitative, was assessed following initial infection, and the course of infection was monitored by culturing vaginal samples collected every $2-7$ days following reinfection.

Results: Serovar D was both more virulent (longer duration of infection) and immunogenic (higher level of circulating and vaginal $\lg G$ and higher incidence of $\lg A$ in vaginal secretions) in the mouse genital tract. Although both serovars induced cross-reacting antibodies during the course of primary infection, prior infection with serovar $\mathrm{H}$ resulted in only a slight reduction in the median duration of infection against homotypic reinfection $(p \sim 0.10)$, while prior infection with serovar $D$ resulted in significant reduction in the median duration of infection against both homotypic $(p<0.0 \mathrm{I})$ and heterotypic reinfection $(p<0.0 \mathrm{I})$ when compared to primary infection in age and conditions matched controls.

Conclusion: Serovar D infection resulted in significant homotypic and heterotypic protection against reinfection, while primary infection with serovar $\mathrm{H}$ resulted in only slight homotypic protection. In addition to being the first demonstration of acquired heterotypic immunity between human oculogenital serovars, the differences in the level and extent of this immunity could in part explain the stable difference in serovar prevalence among human isolates. 


\section{Background}

Chlamydia trachomatis is the most common bacterial pathogen associated with sexually transmitted genital tract infections both in the United States [1] and worldwide [2]. It is generally accepted that most female genital tract infections with C. trachomatis are both asymptomatic and without severe sequelae [3]; and, that despite improved screening programs and the availability of highly effective antibiotics [4-6], there has been a significant increase in the incidence of $C$. trachomatis genital tract infection within the last half decade [2,7]. Although epidemiologic studies suggest that prior infection with $C$. trachomatis confers some short term protection against reinfection $[8,9]$, the exact nature of this acquired immunity remains undetermined as do issues relating to the serovar specificity and possible involvement of this immunity in the more severe sequelae associated with multiple and/or chronic infection [10-12].

It has been advanced that serovar specific immune responses, particularly those made to the major outer membrane protein (MOMP), contribute to protection, whereas responses to broadly shared antigens, particularly those induced by chlamydial heat shock protein 60 (Hsp60), are associated with the immunopathologic injury that contributes to ectopic pregnancy and tubal infertility [13-19]. There is also increasing evidence from both human epidemiologic studies and animal model experiments to support the hypothesis that a protective immune response to reinfection is a complex, site of infection variable interaction between $C$. trachomatis and specific Th1 dominant cellular responses and interferongamma mediated Th1 augmenting humoral responses $[20,21]$.

In attempts to understand the salient features and specific components of this interplay, a great deal of work has been performed using slightly modified versions of a murine model of female genital tract infection first described by Tuffrey and Taylor-Robinson [22]. In our laboratory, we routinely use strains belonging to the human oculogenital biovar of $C$. trachomatis and have previously reported significant differences in the course of infection among strains belonging to 7 oculogenital serovars, which loosely correlated with the prevalence of the serovars among human clinical isolates, especially for the most and least prevalent serovars, i.e. D and E versus $H$ and I [23].

The purpose of the present study was to expand on these observations by assessing the degree of homotypic and heterotypic protection against reinfection that follows resolution of infection with human isolates of C. trachomatis. Two strains were selected from the previously studied collection of strains: the strain of serovar D which was shown to establish the longest duration of infection (median duration of 38 days) and greatest humoral response; and the serovar $\mathrm{H}$ strain which had the shortest duration (median duration of 7 days) and lowest humoral response. In addition, lower genital tract infection with serovar D was shown to both ascend into the uterine horns with a greater frequency than serovar $\mathrm{H}$, as well as shed more infectious units during the acute phase of infection [23]. In a separate study we demonstrated a link between certain in vitro growth characteristics and differences in the level of cytotoxic activity associated with elementary bodies between these strains [24]. Thus, strain selection was made with the intention of reflecting the greatest diversity observed among the strains studied in the murine model, as well as to represent serovars that have significantly different prevalence rates among human isolates in the hope that the results of the study would provide some insight into the possible causes of these differences. Duration of genital tract infection was used to determine the extent of protection, and humoral and cellular immune response data were evaluated to identify factors that associated with any observed protection.

\section{Methods \\ Animals}

Outbred CF-1 female mice (Charles River Labs) were purchased at 7 weeks of age and were allowed to acclimate for one week prior to use. All experiments were conducted in a BL-2 containment facility in compliance with animal care regulations and under protocols approved by the institutional research animal care committee.

\section{Bacteria and culture technique}

Mycoplasma-free and pure PCR-typed strains of serovar D and $\mathrm{H}[23,24]$ were propagated, purified, titrated, and isolated in cycloheximide treated McCoy cell monolayers using standard techniques. Separate vials of the same $70^{\circ} \mathrm{C}$ stored stocks were used for both infections.

\section{Murine model}

Progesterone, in the form of medroxyprogesterone acetate (Depo-Provera, Upjohn), was given subcutaneously (sc) in $2.5 \mathrm{mg}$ doses, 10 and 3 days prior to infection [22,23]. Prior to infection, vaginal specimens were obtained for culture and cytology, and 2 hours later mice were inoculated intravaginally by direct instillation of $25 \mu \mathrm{l}$ of sucrose phosphate buffered transport medium (SP) containing 1-3 × $10^{7}$ inclusion forming units (ifu).

\section{Sample collection}

The presence of Chlamydia in the lower genital tract was determined by swabbing the vaginal vault and ectocervix with a calcium alginate swab, which was cultured for the organism. Plasma and vaginal secretions were obtained 
Table I: Acquired Homotypic and Heterotypic Immunity Against Oculogenital Chlamydia trachomatis Serovars Following Female Genital Tract Infection in Mice

\begin{tabular}{|c|c|c|c|c|c|c|c|c|c|c|c|c|c|c|c|c|c|c|c|c|c|c|}
\hline \multicolumn{2}{|c|}{ Infection Serovar } & \multirow{2}{*}{$\begin{array}{l}\text { Number } \\
\text { of } \\
\text { Animals }\end{array}$} & \multicolumn{18}{|c|}{ Number of Animals Culture Positive on Reinfection Day } & \multirow{2}{*}{$\begin{array}{l}\text { Median } \\
\text { Duration } \\
\text { of } \\
\text { Infection }\end{array}$} & \multirow{2}{*}{$\begin{array}{c}\text { Wilcoxon } \\
\text { Rank Sum } \\
\text { p Value }\end{array}$} \\
\hline Initial! & Reinfection & & 2 & 4 & 6 & 8 & 10 & 14 & 17 & 21 & 24 & 28 & 31 & 35 & 38 & 42 & 45 & 48 & 52 & 55 & & \\
\hline $\mathrm{D}$ & $\mathrm{H}$ & 12 & 12 & 5 & 3 & 2 & 5 & 2 & I & 0 & 0 & 0 & 0 & 0 & 0 & 0 & 0 & 0 & 0 & 0 & 5 & $<0.01$ \\
\hline $\mathrm{H}$ & $\mathrm{H}$ & 12 & 12 & 11 & 8 & 8 & 10 & 3 & 1 & 2 & 0 & 0 & 0 & 0 & 0 & 0 & 0 & 0 & 0 & 0 & 10 & $\sim 0.10$ \\
\hline None & $\mathrm{H}$ & 12 & 12 & 12 & 12 & 12 & 11 & 6 & 5 & 2 & 2 & 1 & 0 & 0 & I & 0 & 0 & 0 & 0 & 0 & 15.5 & -- \\
\hline$D$ & D & 12 & 12 & 9 & 7 & 9 & 7 & 5 & 4 & 2 & 2 & I & 0 & 0 & 0 & 0 & 0 & 0 & 0 & 0 & 12 & $<0.01$ \\
\hline $\mathrm{H}$ & D & 12 & 12 & 12 & 12 & 12 & II & 6 & 10 & 7 & 7 & 4 & I & 2 & I & 0 & 0 & 0 & 0 & 0 & 24 & NS \\
\hline None & $D$ & 12 & 12 & 12 & 12 & 12 & 11 & 7 & 5 & 6 & 4 & 4 & 2 & 1 & 1 & 2 & 0 & 0 & 0 & 0 & 22.5 & -- \\
\hline
\end{tabular}

IMedian duration of infections during the primary infection phase of this study were 10 days with serovar $\mathrm{H}$ and 33 days with serovar $\mathrm{D}$.

prior to infection. Blood was taken from a small tail vein incision, diluted 1:10 in PBS, and the plasma (P) was separated by centrifugation. Vaginal secretions (VS) were collected over a two-hour period by absorption into a piece of surgical sponge, and eluted into $400 \mu \mathrm{l}$ of PBS. All samples were frozen at $-20^{\circ} \mathrm{C}$ until tested.

\section{Serological analyses}

Anti-chlamydial IgG and IgA titers in blood and vaginal secretions were determined by indirect solid phase enzyme immunoassay (EIA) using SDS solubilized Ct elementary bodies as antigen. Western immunoblot analysis were performed on a similar antigen preparation which had been SDS-PAGE separated and transferred to nitrocellulose paper. After incubation with sample ( $\mathrm{P}$ at a final dilution1:200; VS at a final dilution of 1:20), reactive bands were visualized with standard EIA reagents.

\section{Spleen cell analysis}

Cellular immune responses were determined using a standard assay for ${ }^{3} \mathrm{H}$-thymidine $\left({ }^{3} \mathrm{H}-\mathrm{Td}\right)$ incorporation. Specific responses were measured using formalin preserved elementary bodies (EB) at a ratio of 100 EB:1 spleen cell, and non-specific responses measured using concavalin A (Con A) at $2 \mu \mathrm{g} / \mathrm{ml}$, phytohemagglutinin (PHA) at $5 \mu \mathrm{g} / \mathrm{ml}$, and lipopolysaccharide (LPS) at 100 $\mu \mathrm{g} / \mathrm{ml}$. Single-cell suspensions were prepared by gently pressing the spleen through a nylon sieve. Debris was allowed to settle for $2 \mathrm{~min}$, and the supernatant containing single cells was spun down at $500 \times \mathrm{g}$ for 10 minutes. Erythrocytes were lysed with $\mathrm{NH}_{4} \mathrm{Cl}$ solution and cells were washed three times with RPMI 1640 medium containing $10 \%$ fetal bovine serum and plated in triplicate, in 96-well plates at a concentration of $5 \times 10^{5}$ cells per well. Proliferative responses were measured by uptake of $1 \mu \mathrm{Ci}$ of ${ }^{3} \mathrm{H}$-thymidine $\left({ }^{3} \mathrm{HTd}\right)$ per well for the last 24 hours of a 72 hour incubation period. As a measure of response, a stimulation index (SI) was calculated $\left(\mathrm{SI}={ }^{3} \mathrm{H}\right.$-Td incorpo- ration with stimulation $/{ }^{3} \mathrm{HTd}$ incorporation without stimulation).

\section{Statistical evaluation}

Duration of infection data were analyzed by the Wilcoxon Rank Sum Test; meaned data by F-Test; and frequency data by Chi Square.

\section{Results}

Homotypic and heterotypic protection against reinfection Consistent with our previous report [23], intravaginal inoculation with the serovar $\mathrm{D}$ strain resulted in a longer duration of infection in previously uninfected mice compared with the serovar $H$ strain (22.5 days versus 15.5 days, $\mathrm{p}=0.05$ ) (Table 1 ). Analysis of the effect of prior $C$. trachomatis genital tract infection on the duration of infection following homotypic and heterotypic reinfection showed that infection with serovar $\mathrm{H}$ resulted in only slight homotypic protection (15.5 days versus 10 days duration of infection: $p=0.1$, while serovar $D$ infection resulted in significant homotypic (22.5 days versus 12 days duration of infection: $\mathrm{p}<0.01$ ) and heterotypic protection ( 15.5 days versus 5 days duration of infection: $\mathrm{p}<$ 0.01 ) against reinfection (Table 1 ).

\section{Humoral immune responses \\ Quantitative}

As in our previous study [23], genital tact infection with serovar D resulted in a significantly greater quantitative anti-chlamydial humoral response compared to the response to serovar $\mathrm{H}$ infection (Table 2). Serovar $\mathrm{D}$ induced significantly higher plasma $(\mathrm{p}<0.05)$ and vaginal ( $p<0.05)$ IgG levels as compared to serovar H. Although no quantitative differences between the IgA responses following infection with either serovar $\mathrm{D}$ and $\mathrm{H}$ were observed in the vaginal secretions of animals with detectable levels of antibody, a significant difference was observed in the frequency of IgA positive vaginal secre- 
Table 2: Serologic Analysis of Plasma and Vaginal Secretions Following Infection and Immediately Prior to Reinfection with Chlamydia trachomatis Serovars D and $\mathbf{H}$

\begin{tabular}{|c|c|c|c|c|c|c|c|c|}
\hline & & & \multicolumn{6}{|c|}{ Plasma and Vaginal Secretion Titers ( $\left.\log _{2}\right)(p$ Value) } \\
\hline \multicolumn{2}{|c|}{ Infection Serovar } & \multirow{2}{*}{$\begin{array}{c}\text { Number of } \\
\text { Animals }\end{array}$} & \multicolumn{2}{|c|}{ Plasma IgG } & \multicolumn{2}{|c|}{ VS $\lg G$} & \multicolumn{2}{|c|}{ VS IgA' } \\
\hline Primary & Secondary & & $\mathrm{H}$ & $\mathrm{D}$ & $\mathrm{H}$ & $\mathrm{D}$ & $\mathrm{H}$ & $\mathrm{D}$ \\
\hline \multirow[t]{2}{*}{$D$} & $\mathrm{H}$ & 12 & 13.0 & 13.6 & 8.3 & 8.7 & 7.2 & 8.3 \\
\hline & & & \multicolumn{2}{|c|}{$(<0.05)$} & \multicolumn{2}{|c|}{$(<0.05)$} & \multicolumn{2}{|c|}{ (NS) } \\
\hline $\mathrm{H}$ & $\mathrm{H}$ & 12 & 11.0 & 11.2 & 5.3 & 6.1 & 6.7 & 6.8 \\
\hline None & $\mathrm{H}$ & 12 & $<6$ & $<6$ & $<2$ & $<2$ & $<2$ & $<2$ \\
\hline \multirow[t]{2}{*}{$D$} & $D$ & 12 & 12.5 & 13.1 & 7.8 & 8.3 & 7.3 & 7.6 \\
\hline & & & \multicolumn{2}{|c|}{$(<0.05)$} & \multicolumn{2}{|c|}{$(<0.05)$} & \multicolumn{2}{|c|}{ (NS) } \\
\hline $\mathrm{H}$ & $D$ & 12 & 11.4 & 11.4 & 5.3 & 5.5 & 6.0 & 6.4 \\
\hline None & $D$ & 12 & $<6$ & $<6$ & $<2$ & $<2$ & $<2$ & $<2$ \\
\hline
\end{tabular}

IValues listed are the mean titers of IgA positive animals only.

tions from serovar $\mathrm{H}$ and $\mathrm{D}$ infected animals prior to reinfection $(11 / 24$ for $\mathrm{H}$ vs $21 / 24$ for $\mathrm{D}, \mathrm{p}<0.01$, data not shown). In all cases, similar homologous and heterologous antibody titers were detected against both antigen preparations used in the assay.

\section{Qualitative}

Tables 3 and 4 contain the Western immunoblot analysis of plasma and vaginal secretions from representative animals following resolution of initial infection and immediately prior to reinfection with serovar $\mathrm{H}$ (Table 3 ) or with serovar D (Table 4). Consistent with the quantitative findings, plasma and vaginal secretions from serovar D infected mice contained antibodies to a greater array of antigens than specimens from serovar $\mathrm{H}$ infected mice; and although often more intense when homologous, plasma from mice infected with either serovar gave similar immunoblot patterns against both antigen preparations, thus demonstrating the induction of a high level of crossreacting IgG during infection.

With the exception of the link between quantitative humoral response and protection, statistical analysis of the serologic and duration of infection data did not detect a humoral factor(s) that correlated with the shorter duration of infection observed following reinfection.

\section{Splenic lymphocyte responses}

Table 5 summarizes the chlamydia-specific and mitogen non-specific splenic lymphocyte responses obtained from groups of four animals 55 days following genital tract inoculation with either serovar $\mathrm{H}$ or $\mathrm{D}$. Mean responses to PHA and both elementary body preparations were greater following infection with either serovar when compared to

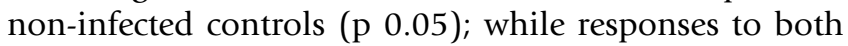
Con-A and LPS were not different from controls. No association could be found between a particular pattern or magnitude of cellular responses and an individual animals duration of infection.

\section{Discussion}

Using a murine model of $C$. trachomatis female genital tract infection, we have demonstrated that homotypic immunity against reinfection was induced following initial infection with either serovar $\mathrm{D}$ or $\mathrm{H}$, but that a more significant level of protection was observed following infection with serovar D. However, heterotypic protection against reinfection was strain dependant and was seen only when the initial infection was with the more virulent and immunogenic strain of serovar D. These results are the first demonstration of heterotypic immunity between two oculogenital serovars following female genital tract infection in the mouse model, as well as being the first

Table 5: Splenic Lymphocyte Responses 55 Days After Primary Infection with Serovars H and D

\begin{tabular}{|c|c|c|c|c|c|}
\hline \multirow[b]{3}{*}{ Group } & \multicolumn{5}{|c|}{ Mean Stimulation Index \pm I SEM } \\
\hline & \multicolumn{2}{|c|}{ EB Serovar } & \multicolumn{3}{|c|}{ Standard Mitogens } \\
\hline & $\mathrm{H}$ & $\mathrm{D}$ & Con-A & PHA & LPS \\
\hline Control & $13.0 \pm 1.7$ & $15.9 \pm 1.8$ & $79.5 \pm 12.0$ & $6.2 \pm 1.8$ & $58.4 \pm 5.3$ \\
\hline $\mathrm{H}$ & $19.2 \pm 3.1^{*}$ & $23.4 \pm 4.1^{*}$ & $96.2 \pm 15.6$ & $11.3 \pm 6.4^{*}$ & $58.7 \pm 15.8$ \\
\hline $\mathrm{D}$ & $19 \pm 1.5^{*}$ & $21.7 \pm 1.7^{*}$ & $78.8 \pm 6.8$ & $11.9 \pm 6.4^{*}$ & $51.1 \pm 6.3$ \\
\hline
\end{tabular}

*Significantly different from Control mean at p 0.05 
Table 3: Serological Analysis of Plasma and Vaginal Secretions from Representative Animals Following Primary Infection with Either Chlamydia trachomatis Serovar H or D and Immediately Prior to Infection with Serovar H

\begin{tabular}{|c|c|c|c|c|c|c|c|c|c|c|c|c|}
\hline \multirow[b]{2}{*}{ Animal } & \multicolumn{6}{|c|}{ H Primary Infection } & \multicolumn{6}{|c|}{ D Primary Infection } \\
\hline & JI & $\mathrm{H} 3$ & $\mathrm{~J} 3$ & $\mathrm{LI}$ & $\mathrm{H} 4$ & $\mathrm{~J} 2$ & RI & $X I$ & $\times 2$ & R4 & $\mathrm{T} 2$ & Y4 \\
\hline & \multicolumn{12}{|c|}{ Infection Duration (Days) } \\
\hline Primary & 24 & 24 & 8 & 24 & 6 & 24 & 38 & 42 & 24 & 42 & 28 & 42 \\
\hline Secondary & 2 & 4 & 10 & 10 & 21 & 21 & 2 & 2 & 4 & 6 & 14 & 17 \\
\hline
\end{tabular}

Plasma and Vaginal Secretion Titers (Log 2) and IgG Immunoblot Reactions Against serovar H and D

\begin{tabular}{ccccccccccccccccccccccccccc}
\hline & $H$ & $D$ & $H$ & $D$ & $H$ & $D$ & $H$ & $D$ & $H$ & $D$ & $H$ & $D$ & $H$ & $D$ & $H$ & $D$ & $H$ & $D$ & $H$ & $D$ & $H$ & $D$ & $H$ & $D$ \\
$P \operatorname{lgG}$ & 14 & 13 & 13 & 13 & 7 & 8 & 13 & 13 & 7 & 8 & 13 & 13 & 12 & 13 & 13 & 14 & 13 & 13 & 14 & 14 & 13 & 13 & 12 & 13 \\
$V \lg$ & 8 & 8 & 8 & 8 & 2 & 3 & 9 & 9 & $<2$ & $<2$ & 8 & 9 & 7 & 8 & 8 & 7 & 8 & 9 & 8 & 8 & 8 & 8 & 8 & 8 \\
$V \lg A$ & 9 & 8 & 8 & 8 & $<2$ & $<2$ & 8 & 8 & $<2$ & $<2$ & 4 & 4 & 5 & 7 & 8 & 9 & 7 & 8 & 7 & 8 & 8 & 9 & 8 & 9 \\
\hline
\end{tabular}

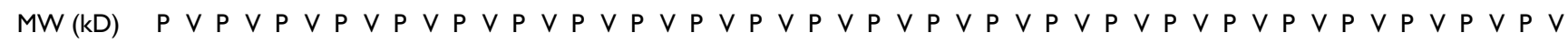

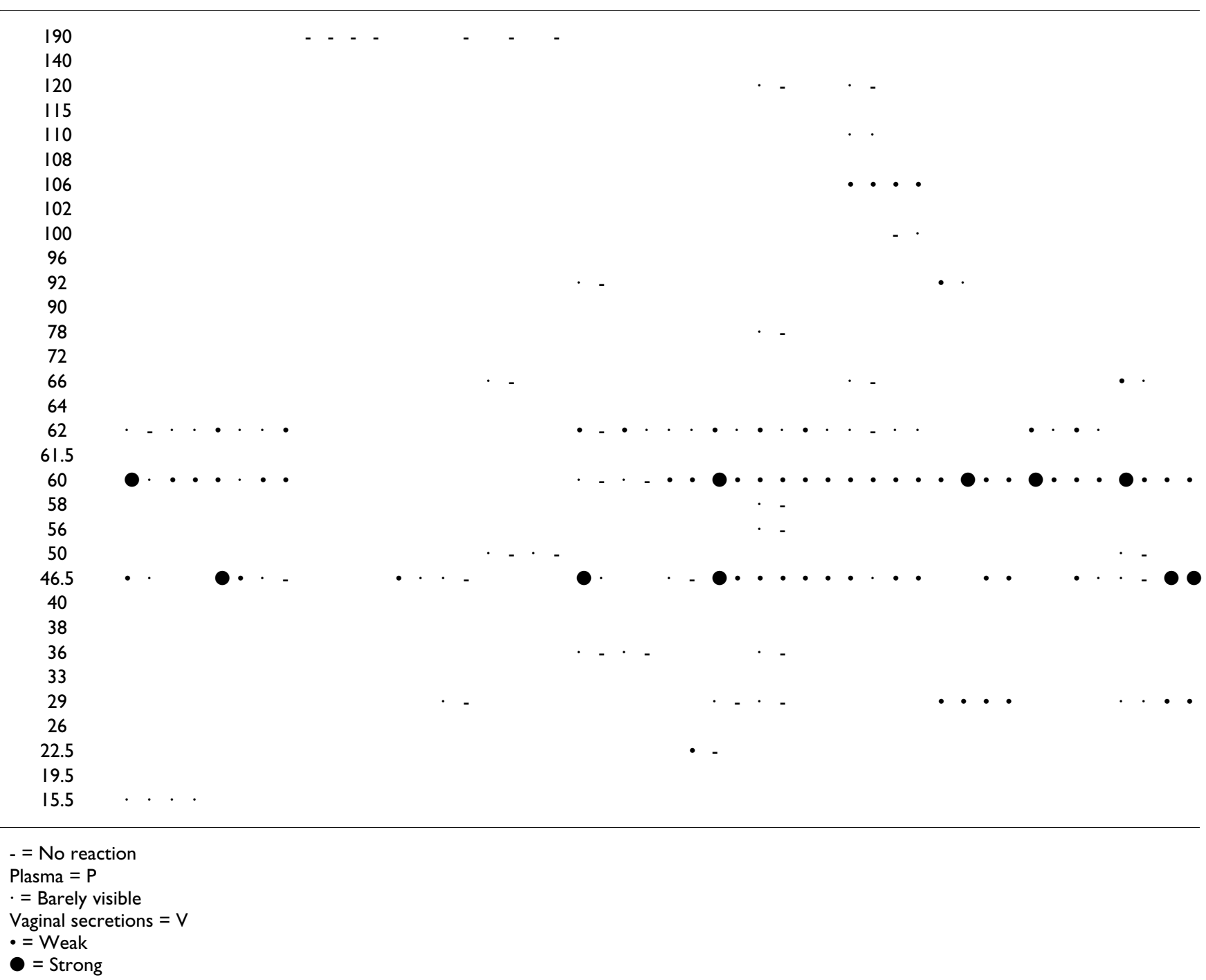


Table 4: Serological Analysis of Plasma and Vaginal Secretions from Representative Animals Following Primary Infection with Either Chlamydia trachomatis Serovar H or D and Immediately Prior to Infection with Serovar D

\begin{tabular}{|c|c|c|c|c|c|c|c|c|c|c|c|c|}
\hline \multirow[b]{2}{*}{ Animal } & \multicolumn{6}{|c|}{ H Primary Infection } & \multicolumn{6}{|c|}{ D Primary Infection } \\
\hline & II & G3 & $\mathrm{K} 2$ & $\mathrm{G} 2$ & $\mathrm{~K} 3$ & 14 & $\mathrm{ZI}$ & S4 & Q4 & $\mathrm{Z2}$ & Q2 & SI \\
\hline & \multicolumn{12}{|c|}{ Infection Duration (Days) } \\
\hline Primary & 6 & 10 & 6 & 31 & 14 & 6 & 45 & 21 & 14 & 45 & 52 & 10 \\
\hline Secondary & 10 & 17 & 24 & 28 & 35 & 38 & 2 & 4 & 10 & 14 & 24 & 28 \\
\hline
\end{tabular}

Plasma and Vaginal Secretion Titers ( $\left.\log _{2}\right)$ and IgG Immunoblot Reactions Against serovar H and D

\begin{tabular}{|c|c|c|c|c|c|c|c|c|c|c|c|c|c|c|c|c|c|c|c|c|c|c|c|c|}
\hline & $\mathrm{H}$ & $\mathrm{D}$ & $\mathrm{H}$ & $D$ & $\mathrm{H}$ & $D$ & $\mathrm{H}$ & $D$ & $\mathrm{H}$ & $D$ & $\mathrm{H}$ & $D$ & $\mathrm{H}$ & $D$ & $\mathrm{H}$ & $\mathrm{D}$ & $\mathrm{H}$ & $D$ & $\mathrm{H}$ & $D$ & $\mathrm{H}$ & $D$ & $\mathrm{H}$ & $\mathrm{D}$ \\
\hline$P \lg G$ & 11 & 11 & 13 & 13 & 11 & 11 & 12 & 12 & 9 & 9 & 13 & 11 & 14 & 14 & 12 & 13 & II & 11 & 13 & 14 & 14 & 14 & II & 11 \\
\hline$V \lg G$ & 5 & 5 & 7 & 6 & 2 & 4 & 6 & 7 & 4 & 4 & 5 & 5 & II & 11 & 7 & 7 & 7 & 8 & 9 & 10 & 9 & 9 & 4 & 5 \\
\hline$V \lg A$ & $<2$ & $<2$ & $<2$ & $<2$ & $<2$ & $<2$ & 7 & 8 & $<2$ & $<2$ & $<2$ & 2 & 3 & 5 & $<2$ & $<2$ & 4 & 6 & 8 & 9 & 10 & 9 & $<2$ & $<2$ \\
\hline
\end{tabular}

$M W(k D) \quad P \vee P \vee P \vee P \vee P \vee P \vee P \vee P \vee P \vee P \vee P \vee P \vee P \vee P \vee P \vee P \vee P V P \vee P \vee P V P \vee P V P V P V$

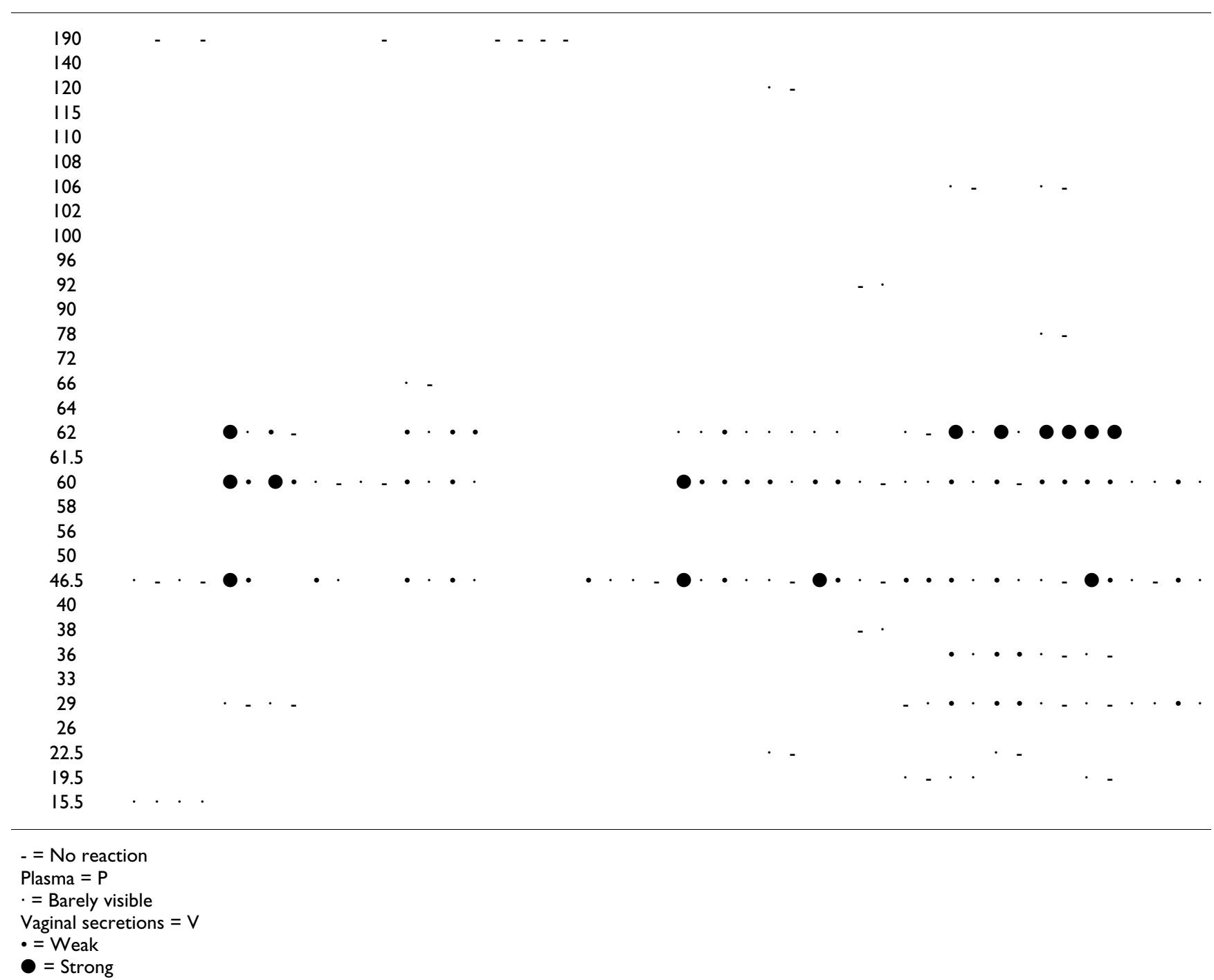


comparative study that suggests a possible strain dependent restriction on the process. The findings are consistent with other studies that have observed heterotypic immunity in the context of MoPn and serovar E. Also consistent with prior reports is the correlation between the level of protection observed and the virulence of the strains used to infect the mouse genital tract, with the more virulent MoPn inducing a more solid level of heterotypic immunity against serovar $\mathrm{E}$ than was observed in the reverse situation [25,26]. Finally, the observed differences in heterotypic and homotypic responses between serovars D and $\mathrm{H}$ could explain in part the relatively stable differences in the frequency of these two serovars among human isolates from different geographic locations [2733 , i.e. a prior infection with a more virulent/immunogenic serovar would confer a greater degree of protection against infection with a less virulent/immunogenic serovar, thus reducing the incidence of the latter by reducing the efficiency of serial transmission.

Consistent with human epidemiologic data $[8,9]$, the protection observed in this model against reinfection with oculogenital serovars of C. trachomatis was not complete, but rather acted in a way that reduced the duration of infection and level of bacterial shedding (data not shown) during infection. With the notable exception that serovar $\mathrm{H}$ infection resulted in a lesser quantitative and qualitative humoral response, a thorough analysis of the individual and collective data was unable to identify any specific element(s) that correlated with protection. This finding is consistent with a report in which a similarly extensive analysis of cellular and humoral responses was performed in a comparison of the acquired immunity induced by infection with MoPn and serovar E [25]. Although not proof, this does support the current working hypothesis that acquired immunity to $C$. trachomatis female genital tract infection is a complex and integrated phenomena that relies on both Th1 and Th2 type responses made during the course of infection, which in turn enhance innate immune responses upon reinfection [20]. This complexity, which likely arises out of the ever changing physiologic and immunologic milieu within and between anatomically distinct but connected regions of the female genital tract, may account for the difficulty identifying specific components of what may be a flexible pattern of responses that lead to a given individual's level of protection against or risk of severe upper genital tract pathology [21].

Women with recurrent $C$. trachomatis infection are at increased risk of reproductive sequelae, including pelvic inflammatory disease, ectopic pregnancy and tubal infertility [10-12], which have been linked to both cellular and humoral immune responses induced during infection [13-19]. How the nature and level of homotypic and/or extent of heterotypic immunity in the murine model extrapolate to the risk of upper genital tract pathology and infertility was not assessed in this study, and is an area of investigation that has yet to be systematically addressed. Most of the experimental data relating to the severe sequelae associated with $C$. trachomatis female genital tract infection has been obtained in studies using C. muridarum, MoPn [34,35]. As a result, it has not been possible to clearly assess the immunologic features that are thought to contribute to severe sequelae within the human female genital tract, because the damage that occurs within the murine genital tract following infection with MoPn is a consequence of acute and not chronic infectious processes and/or recurrent infection [36,37]. Typically in the mouse and in most women, human oculogenital serovars are limited in their ability to ascend with any major pathologic consequence from the initial site of infection within the lower genital tract. However, infection of female $\mathrm{C} 3 \mathrm{H} / \mathrm{HeN}$ with a strain of serovar $\mathrm{E}$ has been shown to ascend and cause infertility without gross pathology at a low incidence following a single infection and with increased incidence upon reinfection [26]. Of particular interest is that none of these mice developed hydrosalpinx, which is the hallmark of upper tract infection with MoPn, indicating a possible alternative mechanism for the induction of infertility, one different from the tubal dilation, scarring and associated hydosalpinx that occurs as a sequelae to MoPn infection. Although no specific immunologic mechanism was identified as contributing to the development of infertility, it was noted that the $\mathrm{C} 3 \mathrm{H} / \mathrm{HeN}$ mouse is an $\mathrm{Hsp} 60$ responding strain and that Hsp60 responding strains of mice are more susceptible to MoPn induced infertility while non-responders can be infected but do not experience severe upper tract pathology. It will be worthwhile to determine if the two $C$. trachomatis strains used in the present study show a similar relationship to each other in $\mathrm{C} 3 \mathrm{H} / \mathrm{HeN}$ mice and whether homotypic and/or heterotypic elements of immunity play a role in the progression of events that lead to severe upper tract pathology, which is essentially the reason why $C$. trachomatis genital tract infections are significant and why intervention and prevention strategies are needed.

\section{Conclusion}

In conclusion, we demonstrate in the first study comparing phenotypically different strains representing two human oculogenital serovars that both the level of homotypic protection against reinfection and the ability to confer heterotypic protection correlated with the virulence/ immunogenicity of the strain. Extrapolating the results to human epidemiologic data could explain in part the relatively stable differences in the frequency between the most and least prevalent serovars based on a serovars ability to induce or not induce heterotypic immunity. Although no 
specific cellular or humoral factor(s) could be identified that associated with the observed protection, it is clear that heterotypic immunity can be induced and that the systematic study of human oculogenital serovars in the mouse model of female genital tract infection could provide information that leads to an understanding of what distinguishes a protective from an immunopathic response to infection.

\section{Competing interests}

The author(s) declare that they have no competing interests.

\section{Authors' contributions}

Joseph M. Lyons participated in the design, planning, execution and supervision of the study, and drafted original and final manuscripts. Servaas A. Morré analyzed the data and constructed the tables that appear in the manuscript. Lucy P. Airo-Brown performed the animal experiments and developed the serologic assays used in the study. A. Salvador Peña provided direction during the development of the integrated approach to the study of the Chlamydia trachomatis infections of the female genital tract of which this report is a part. James I. Ito planned and approved the study design, and participated in the preparation of the manuscript. All authors read and approved the manuscript.

\section{Acknowledgements}

This work was supported in part by Public Health Service grant Al-23792 from the National Institute of Allergy and Infectious Diseases.

\section{References}

I. Weinstock H, Berman S, Cates W: Sexually transmitted diseases among American youth: incidence and prevalence estimates, 2000. Perspect Sex Reprod Health 2004, 36:6-I0.

2. Gerbase AC, Rowley JT, Heymann DH, Berkley SF, Piot P: Global prevalence and incidence estimates of selected curable STDs. Sex Trans Infect 1998, 74(SuppI I):SI2-I6

3. van Valkengoed IGM, Morré SA, van den Brule AJC, Meijer CJLM, Bouter LM, Boeke AJP: Overestimation of Complication-rates of Chlamydia trachomatis Screening programs: implications for cost-effectiveness analyses. Int J Epidemiol 2004, 33:4I 6-425.

4. Workowski KA, Lampe MF, Wong KG, Watts MB, Stamm WE: Long-term eradication of Chlamydia trachomatis genital infection after antimicrobial therapy: evidence against persistent infection. JAMA 1993, 270:207I-2075.

5. Scholes D, Stergachis A, Heidrich FE, Andrilla H, Holmes KK, Stamm WE: Prevention of pelvic inflammatory disease by screening for cervical chlamydial infection. $N$ Engl J Med 1996, 334: 1362-1366.

6. van Valkengoed IG, Morre SA, van den Brule AJ, Meijer CJ, Bouter LM, van Eijk JT, Boeke AJ: Follow-up, treatment, and reinfection rates among asymptomatic Chlamydia trachomatis cases in general practice. Br J Gen Pract 2002, 52(48I):623-627.

7. Miller WC, Ford CA, Morris M, Handcock MS, Schmitz JL, Hobbs MM, Cohen MS, Harris KM, Udry JR: Prevalence of chlamydial and gonococcal infections among young adults in the United States. JAMA 2004, 291:2229-2236.

8. Barnes RC, Roddy RE, Stamm WE: Serovars of Chlamydia trachomatis causing repeated genital infections. In Chlamydial Infections. Proceedings of the Sixth International Symposium on Human Chlamydial Infections Edited by: Oriel D, Ridgeway G, Schachter J, Tay-
lor-Robinson D, Ward M. Cambridge, UK, Cambridge University Press; 1986:503-507.

9. Rietmeijer CA, van Bemmelen R, Judson FN, Douglas JM: Incidence and repeat infection rates of Chlamydia trachomatis among male and female patients in an STD clinic: implications for screening and rescreening. Sex Trans Dis 2002, 29:65-72.

10. Brunham RC, Maclean IW, Binns B, Pelling RW: Chlamydia trachomatis: its role in tubal infertility. J Infect Dis 1985, I 52: | 275- | 282 .

II. Westrom LR, Joesoef R, Reynolds G, Hagdu A, Thompson SE: Pelvic inflammatory disease and fertility. A cohort study of 1,844 women with laparoscopically verified disease and 657 control women with normal laparoscopic results. Sex Trans Dis 1992, 19:185-192.

12. Hillis SD, Owens LM, Marchbanks PA, Amsterdam LF, Mac Kenzie WR: Recurrent chlamydial infections increase the risks of hospitalization for ectopic pregnancy and pelvic inflammatory disease. Am J Obstet Gynecol 1997, I 76: I03-I07.

13. Ward ME: The immunobiology and immunopathology of chlamydial infections. APMIS 1995, 103:769-796.

14. Dean D, Oudens E, Bolan G, Padian N, Schachter J: Major outer membrane protein variants of Chlamydia trachomatis are associated with severe upper genital tract infections and histopathology in San Francisco. J Infect Dis 1995, I 72:1013-1022.

15. Lampe MF, Wong KG, Stamm WE: Sequence conservation in the major outer membrane protein gene among Chlamydia trachomatis strains isolated from the upper and lower urogenital tract. J Infect Dis 1995, I 72:589-592.

16. Brunham RC, Peeling RW: Chlamydia trachomatis antigens: role in immunity and pathogenesis. Infect Agents Dis 1997, 3:2 I 8-233.

17. Eckert LO, Hawes SE, Wolner-Hanssen P, Money DM, Peeling RW, Brunham RC, Stevens CE, Eschenbach DA, Stamm WE: Prevalence and correlates of antibody to chlamydial heat shock protein in women attending sexually transmitted disease clinics and women with confirmed pelvic inflammatory disease. J Infect Dis 1997, I 75: |453-|458.

18. Domeika M, Domeika K, Paavonen J, Mardh PA, Witkin SS: Humoral immune response to conserved epitopes of Chlamydia trachomatis and human $60-\mathrm{kDa}$ heat-shock protein in women with pelvic inflammatory disease. J Infect Dis 1998, I 77:7 I4-7I9.

19. Kinnunen A, Molander P, Morrison R, Lehtinen M, Karttunen R, Tiitinen A, Paavonen J, Surcel HM: Chlamydial heat shock protein 60 - specific $\mathbf{T}$ cells in inflamed salpingeal tissue. Fertil Steril 2002, 77:162-166.

20. Stephens RS: The cellular paradigm of chlamydial pathogenesis. Trends Microbiol 3003, I I:44-5I.

21. Kelly KA: Cellular immunity and Chlamydia genital infection: induction, recruitment, and effector mechanisms. Int Rev Immunol 2003, 22:3-4I.

22. Tuffrey $M$, Taylor-Robinson D: Progesterone as a key factor in the development of a mouse model for genital-tract infection with Chlamydia trachomatis. FEMS Micribiol Lett 1988, I2: I |1-I|5.

23. Ito Jl, Lyons JM, Airo-Brown LP: Variation in virulence among oculogenital serovars of Chlamydia trachomatis in experimental genital tract infection. Infect Immun 1990, 58:2021-3.

24. Lyons JM, Ito JI, Peña AS, Morré SA: Differences in the growth characteristics and elementary body associated cytotoxin activity between Chlamydia trachomatis oculogenital serovars $\mathbf{D}$ and $\mathbf{H}$ and Chlamydia muridarum (MoPn). J Clin Pathol 2005, 58:397-40I.

25. Ramsey KH, Cotter TW, Salyer RD, Miranpuri GS, Yanez MA, Poulsen CE, DeWolfe JL, Byrne GI: Prior genital tract infection with a murine or human biovar of Chlamydia trachomatis protects mice against heterotypic challenge infection. Infect Immun 1999, 67:3019-3025.

26. Ramsey KH, DeWolfe JL, Salyer RD: Disease outcome subsequent to primary and secondary urogenital infection with murine or human biovars of Chlamydia trachomatis. Infect Immun 2000, 68:7186-7I89.

27. Barnes RC, Rompalo AM, Stamm WE: Comparison of Chlamydia trachomatis serovars causing rectal and cervical infections. J Infect Dis 1987, I 56:953-958.

28. Kuo CC, Wang SP, Holmes KK, Grayston TJ: Immunotypes of Chlamydia trachomatis isolates in Seattle, Washington. Infect Immun | 983, 4 I :865-868. 
29. Mabey DC, Forsey WT, Treharne JD: Serotypes of Chlamydia trachomatis in The Gambia. Lancet 1987, 2:452.

30. Wagenvoort JHT, Suchland RJ, Stamm WE: Serovar distribution of urogenital Chlamydia trachomatis strains in The Netherlands. Genitourin Med 1988, 64:159-161.

31. Morré SA, Rozendaal L, van Valkengoed IG, Boeke AJ, van Voorst Vader PC, Schirm J, de Blok S, van Den Hoek JA, van Doornum G], Meijer CJ, van Den Brule AJ: Urogenital Chlamydia trachomatis serovars in men and women with a symptomatic or asymptomatic infection: an association with clinical manifestations? J Clin Microbiol 2000, 38:2292-2296.

32. Suchland RJ, Eckert LO, Hawes SE, Stamm WE: Longitudinal assessment of infecting serovars of Chlamydia trachomatis in Seattle public health clinics: 1988-1 996. Sex Transm Dis 2003, 30:357-361.

33. Spaargaren J, Verhaest I, Mooij S, Smit C, Fennema HS, Coutinho RA, Peña AS, Morré SA: Analysis of Chlamydia trachomatis serovar distribution changes in the Netherlands (1986-2002). Sex Transm Infect 2004, 80: I5I-I52.

34. de la Maza LM, Pal S, Khamesipour A, Peterson EM: Intravaginal inoculation of mice with the Chlamydia trachomatis mouse pneumonitis biovar results in infertility. Infect Immun 1994, 62:2094-2097.

35. Darville T, Andrews CW, Laffoon KK, Shymasani W, Kishen LR, Rank RG: Mouse strain-dependent variation in the course and outcome of chlamydial genital tract infection is associated with differences in host response. Infec Immun 1997, 65:3065-3073.

36. Morrison RP, Caldwell HD: Immunity to murine chlamydial genital infection. Infect Immun 2002, 70:274I-5I.

37. Morré SA, Lyons JM, Ito JI Jr: Murine models of Chlamydia trachomatis genital tract infection: use of mouse pneumonitis strain versus human strains. Infect Immun 2000, 68:7209-72II.

\section{Pre-publication history}

The pre-publication history for this paper can be accessed here:

http://www.biomedcentral.com/1471-2334/5/105/pre

pub

Publish with Biomed Central and every scientist can read your work free of charge

"BioMed Central will be the most significant development for disseminating the results of biomedical research in our lifetime. "

Sir Paul Nurse, Cancer Research UK

Your research papers will be:

- available free of charge to the entire biomedical community

- peer reviewed and published immediately upon acceptance

- cited in PubMed and archived on PubMed Central

- yours - you keep the copyright

Submit your manuscript here:

http://www.biomedcentral.com/info/publishing_adv.asp
BiolMedcentral 